\title{
Peplau and the brain: Why I nterpersonal Neuroscience provides a useful language for the relationship process
}

\author{
Kathleen R Delaney ${ }^{1}$, J ulie Ferguson ${ }^{2}$ \\ 1. Department of Community, Rush University, Chicago, USA. 2. St John of God, Raphael Centre, Blacktown, Australia.
}

Correspondence: Kathleen R Delaney. Address: Department of Community, Systems and Mental Health, Rush College of Nursing, Chicago, USA. Email: Kathleen_R_Delaney@rush.edu

Received: February 11, 2014

Accepted: May 27, 2014

Online Published: June 9, 2014

DOI : 10.5430/jnep.v4n8p145

URL: http://dx.doi.org/10.5430/jnep.v4n8p145

\begin{abstract}
Since introduced by Peplau in the 1950's the psychotherapeutic relationship has been a defining element of psychiatric mental health (PMH) nursing practice. While the components of the therapeutic relationship have been detailed over the decades, PMH nurses appear to be faltering in particular aspects of the relationship process. Individuals hospitalized on inpatient psychiatric units have reported that nurses often failed to engage. Nursing leaders believe that the specialty has not articulated what PMH nurses do within the relationship that helps clients lead a more meaningful life. We suggest what remains ambiguous is not what nurses do within the relationship but the language to depict the mental processes involved in relationship building particularly in the engagement phase. Using the language of interpersonal neuroscience three key engagement processes are detailed, i.e., resonance, attunement and mentalizing. The healing elements of the relationship are explored particularly how attention to individuals' narratives of experiences supports their movement towards integration and coherence.
\end{abstract}

\section{Key words}

Psychiatric mental health nursing, Psychotherapeutic relationship, Nurse-patient relationship, Interpersonal Neuroscience

\section{I ntroduction}

Pose the question in Google, "What is the mind?" and the search engine’s top response appears: "the element of a person that enables them to be aware of the world and their experiences, to think, and to feel; the faculty of consciousness and thought” ${ }^{[1]}$. This depiction of the mind conjures up an image of an amorphous "thinking component” of one's brain; a part that processes incoming stimuli, information, sensations and then moves these data to an action center. While a valid depiction, in the last 20 years the field of interpersonal neuroscience has introduced a broader perspective of the mind, suggesting one's experience of the mind occurs within distinct patterns of neural activity. At the most basic level this experience of the mind arises from the flow of energy in the brain; energy born from synaptic firing as stimuli from the outside world or from internal sensations, thoughts or memories initiate activity in particular neurons ${ }^{[2]}$. The mind is organized by these firing patterns. Moreover these same patterns organize incoming information since such data triggers (for that individual) a typical neural firing in the brain. This network of firing patterns creates a mental image be it an image that is expressed as a sensation or an object with a linguistic tag. For example the smell of fresh baked cookies might 
create a mental image along with the associations one holds to eating a sweet, the act of baking or perhaps being a recipient of another's warm offering. At this point of association to the cookie smell the individual is having an experience of the mind.

The energy that creates experiences of the mind is influenced by and influences what we take in and what we put forth; a bi-directional energy flow. To grasp this bi-directional idea think of information as the meaning of events; how we represent an experience or another person to ourselves. So a neural firing pattern is symbolic in the sense that how an individual comes to define an event or occurrence is influenced by associations to the event, memories (operating both in and out of awareness) as well as emotions associated with it. For instance when a work colleague annoys us to the point that we perseverate on the situation, one is experiencing the mind calling up associations to the person but also what that person's action represents to us be it disregard, threat, or excessive expectation for performance. This snapshot of interpersonal neuroscience is the first layer of a system that builds to suggest how relationships with self and with others results in growth producing integration of the thinking/feeling/remembering aspects of one's brain; an integration that moves us towards a healthy mind and meaningful life.

\section{Psychiatric mental health nursing and their relationship tradition}

How might psychiatric mental health (PMH) nurses use ideas from interpersonal neuroscience to inform their practice? PMH nurses are trained in multiple sciences (psychiatry, medical science, psychotherapies, neuroscience, and prevention science) but the organizing platform for their practice is intervention within the context of the relationship; as Peplau (1997) succinctly stated "the fact remains the work of nurses occurs during their interaction with patients" ([3] p. 162). Research confirms that interventions psychiatric nurses provide e.g., cognitive behavioural, supportive dynamic or interpersonal, are not as important to patients as the relationships that build within the experience ${ }^{[4]}$. This holds true in intervention scenarios that are short term, such as helping an individual in crisis ${ }^{[5]}$ or in extended therapeutic exploration with individuals dealing with serious mental health issues ${ }^{[6]}$. Interestingly while particular interpersonal and communication elements common to the PMH therapeutic relationship are well recognized ${ }^{[7-9]}$, research suggests hospitalized individual's frequently report that nurses failed to engage with them during inpatient psychiatric treatment ${ }^{[10,11]}$. Similarly contemporary PMH thought leaders believe that psychiatric nurses have failed to clearly articulate what they do with patients within the relationship and the contributions they make to the health of mental health service users ${ }^{[12]}$.

How is it that the relationship element of PMH practice is identified as the critical element of the discipline yet at the same time eludes explication and perhaps consistent enactment? Several dynamics might underlie this conundrum. One possible culprit is the customary way the PMH nurses have come to think about and depict their work with patients. When asked inpatient PMH nurses appear to easily recall anecdotes of their interactions with patients ${ }^{[13]}$. Qualitative investigations attest that PMH nurses tell stories about their relationship work and the approaches they use to forge connections with patients ${ }^{[14]}$. Perhaps PMH nurses think of relationships only in the context of their connection with a particular patient or in terms of activities embedded in every-day practice ${ }^{[15]}$. Berg and Hallberg (2000) maintain such stories are more about doing for patients rather than being with the individual; relationship aspects that are difficult to grasp and articulate ${ }^{[16]}$. If so the relationship elements of PMH practice remain elusive not only because of a proclivity towards case-based depictions but also due to an inability to articulate the mental process and "being with" skills involved in the engagement process.

This is perplexing because from Peplau forward the processes involved in PMH relationship building have been explored and elaborated ${ }^{[17-20]}$. Given the availability of such literature how could the nursing relationship remain ambiguous and

unformulated ${ }^{[21]}$ ? We suggest what remains elusive and ambiguous is not what nurses do but lack of a language to depict 
how they are thinking, sensing and responding to patients as they attempt to forge engagement. As Dziopa \& Ahern (2008) suggested the mental work involved in building a relationship is often treated as instinctive and thus the descriptors fail to define the cognitive/affective processes at play as the relationship proceeds ${ }^{[7]}$. Thus to fully represent the relationship process nurses must couple the actions they take with the cognitive processes utilized to build the therapeutic relationship. If nurses are to realize this goal and verbalize what transpires during therapeutic interactions a language is needed for the cognitive or "being with" components of the relationship process.

Interpersonal neuroscience supplies this language. It brings forward concepts that fit with the engagement process; particularly cognitive mechanisms operating as a PMH nurse mentally moves into the patient's experience of illness. Interpersonal neuroscience has many interconnecting ideas but in this instance we will focus on the mechanisms it suggests when the mind engages during interpersonal interactions. These ideas should help PMH nurses think conceptually about what they attend to and how they use their own affective responses as they forge connections with clients. With these neuroscience concepts nurses will have a language for the putative mental processes at play in building engagement, understanding patients' experiences and for re-shaping narratives such that relationships release their healing capacity ${ }^{[22]}$. The language can also be used to teach new PMH nurses and students about how nurses engage with patients. Finally interpersonal neuroscience revitalizes Peplau's notion of the relationship as therapeutic by bringing a new language to her ideas on healing through integration of experiences.

To mesh Peplau and the language of interpersonal neurobiology three of her relational tenets are examined; the need for nurses to 1) relate meaningfully to the reactions of patients; 2) help the patient become aware of reactions; and 3) get to know the patient's view of self and predicament ${ }^{[3]}$. These three Peplau principles guide the intentional actions that promote the relationship. Drawing from key elements of interpersonal neurobiology we suggest that PMH nurses could use this theory to explain their attunement with patients, how they come to apprehend the patient's state of mind, and how the patient's narrative of illness contributes to their formulation of the individual's core issues.

\section{Development of a relationship base: Interpersonal resonance}

A particularly useful component of Peplau's teaching on the relationship was how the nurse initiated the engagement process. As she instructed nurses needed to relate meaningfully to patients' reactions to their illness, including the psychological and social changes that illness forces on them ${ }^{[23]}$. Inpatient psychiatric nurses often form an in-the-moment response to an individual experiencing an acute exacerbation of illness. Perhaps this individual is disorganized, anxious, frantic or raw from engulfing paranoia. On the other end of the spectrum hospitalized individuals may be dispirited and see no way beyond the darkness that surrounds them. Adolescents may react to their mental distress by normalizing the experience or projecting their problems on the perceived deficiencies of caregivers. In each instance the nurse is set to apprehend that experience and the accompanying affects and reflect back that understanding to the patient. While a seemingly straightforward process research informs us that nurses may be faltering at this initial connection ${ }^{\text {[24] }}$.

Interpersonal neuroscience provides a language that clarifies the elements of this initial engagement building, i.e., to relate meaningfully to the reaction of the patient. The process begins with presence where the nurse by non-verbal mannerisms and expression sends the intention to the patient; "I am here and available, no judging, just listening" [25]. Via responses, eye contact and body language the nurse transmits to the patient the intent of seeking to apprehend what the individual needs; an intent Peplau understood as signaling receptivity and interest ${ }^{[3]}$. This step of the engagement process is easily under estimated. A consultation -liaison nurse related to one of the authors that when she visits patients on the medical units they usually open up to her, often for the first time since admission, leading the nurses on the floor to view her as a" miracle worker." Yet she relates "All I do is sit down.” Interpersonal neuroscience would suggest that with her sitting behavior and expression she is also sending an important intent to listen and to be available to hear the story; an intent the 
patient experiences and responds to. Interpersonal neuroscience places a conceptual structure around this process by postulating that this intention setting begins the focus on the patient's emotional or mental life.

Along with transmitting intention, the PMH nurse's actions are reflecting back to the patient his/her interpretation of the individual's emotional experience. Empathy is a well-known concept described as how one employs observation, reasoning, and knowledge to come to a psychological inference or insight that reflects the patient's emotions ${ }^{[26]}$. In the engagement process the nurse's mind is creating a match to what he/she perceives in the other and with this activity creates an emotional resonance. At this point, on an unconscious or implicit level, nurses may also be sensing and reading their own somatic and affective shifts ${ }^{[27]}$. These processes set up what Dan Siegel (1999) (the scientist/clinician who developed interpersonal neurobiology) terms collaborative communication; the fine tuning of responses where eye contact, facial expressions and gestures are in sync; a process whereby the patient "feels felt" ${ }^{22}$.

Thus in their efforts to relate meaningfully to the patient nurses are drawing upon three cognitive/emotional processes, sending intention, empathy, and collaborative communication. All of this mental effort is done in the service of facilitating resonance such that individual has the experience of feeling felt. In this instance, interpersonal neuroscience couples action with the putative mental activity involved and in doing so clarifies the processes inherent in the nurse's action. By understanding these first steps in engagement PMH nurses can direct attention and awareness to the mental activities involved in the process.

\section{The process behind the mirror: Mentalization}

Peplau instructed that in addition to paying attention to patients' reactions to their illness, the interpersonal relationship demanded that nurses focus on helping patients become aware of and make sense of these reactions. So a component of the engagement process operates on a conscious or explicit level involving not just a felt sense of the patient's reaction but a cognitive grasp of the individual's state of mind. In the developmental realm such activity has been termed mentalization, a mother's capacity to read the child's experience- a process that demands the mother go beyond the concrete and make sense of the child's behavior in light of his/her mental state; i.e., the underlying intentions and emotion ${ }^{[28]}$. Placing this process in the context of interpersonal neurobiology, Siegel (2007) termed such interchanges mindsight; an interaction where an individual comes to make (in his/her mind) a representation of the mind of the other ${ }^{[27]}$. The concepts (mindsight and mentalization) are quite similar; both involve explicit and implicit processes during which individuals interpret their own and another's action as having meaning: an interpretation based on conscious mental activity such as apprehending the beliefs and reasons around illness the patient expresses as well as the underlying affects that may remain unspoken ${ }^{[29]}$.

How in their daily work do PMH nurses use their own mentalizing capacities as they strive to come to "know" the patient's state of mind? Understanding how memories, sensations and the symptoms of an illness may impact the patient's experience nurses look beyond the current presentation of behaviour. They strive to apprehend the patient's state of mind by attending to what is said, his/her affect, all the while integrating these data with knowledge of the patient and the events that are unfolding. The representation that forms in the nurse's mind is also influenced implicitly by his/her somatic reaction to the individual. An example of this process comes to mind that involved a patient one of the authors cared for on an inpatient unit. This individual was experiencing debilitating depression as well as tremendous distress over a physical issue, difficulty urinating. This was a long standing problem exacerbated by her bouts of severe depression. Dealing with the physical issue on successive evenings, we first focused on her current dispirited state, her sense of defeat at the recurring depression as well as her anxiety over her elimination problems. All of those emotions seemed to be swirling around every interaction, feelings which the author often articulated and validated with the patient. In some sense, my capacity to hold in my mind a representation of this patient as having these feelings and intentions allowed her (via my mental representation of it ) to discover her own internal experience ${ }^{[30]}$. 
As Peplau reminded nurses they spend more time with patients than any other professional, a fact probably true both in inpatient and outpatient services. This time factor gives the nurse an opportunity to help the patient become aware of and make some sense of his/her reactions to the current conditions. Understanding what patients are responding to and their needs at that moment brings in the language of mentalization/mindsight since it involves picking up on the individual's verbal message, feelings, and body language to create a "mental match" with the individual's state of mind. Practitioners' efforts to pay attention to their own state of mind help them attune to the patient's state of mind. Thus an essential component of mentalizing is interpreting one's reactions in term of one's own mental state; which brings in the concept of self-reflection. While a practice PMH nurses have long held as essential ${ }^{[31]}$, the concept takes on additional significance when placed in the context of the mentalization process.

How does mindsight/mentalizing connect to the Peplau notion that nurses should help patients become more aware of their reactions to their illness? Thus far the focus has been on mentalizing; the mental activities where nurses' pay attention on purpose to the patient's state of mind and then by their own implicit and explicit self-reflection signal that understanding to the individual. But how does this mental activity relate to a patient focusing on responses to his/her situation? Siegel (2006) believes that with mentalizing "reverberating interactions" occur; interactions through which individuals may be able to experience and become aware of previously unbearable states of activation ${ }^{[27]}$. This relationship concept was echoed by Adnøy Erickson et al. (2014) in their study of nurse-patient engagement and recovery ${ }^{[24]}$. These researchers concluded that when nurses are able to signal they have noticed what is being said and the person feels heard individuals are able to open up to perspectives on their experiences that they might not have considered. In this light connecting with an individual's experience via mentalizing, particularly when accompanied by a respectful, genuine and a nonjudgemental attitude is a preliminary step to exploring with individuals how they make sense of their experiences ${ }^{[32,33]}$.

\section{Stories and the coherent sense of self}

Peplau believed that within the relationship the focus on the patient also facilitates an understanding of the patient's view of self; their rendition of what it is like to be him or her ${ }^{[34]}$. How does the nurse construct this rather intimate knowledge of the other? We see it builds from intentional presence and resonance and mindsight; a process that leads here- apprehending the patient's conscious views of self and his/her situation. Peplau said that this activity involved asking who, what, and where questions to stimulate patients' descriptions and stories. Indeed stories are critical to this process. Narrative theorist see stories as ways individuals frame events; events that have meaning to the individual and which in a sense pull together parts of the self ${ }^{[35]}$. As Hall \& Powell (2011) so succinctly explain, narratives reveal the meanings and emotional impact events have for the client ${ }^{[35]}$.

Interpersonal neurobiology also recognizes the importance of the narrative emphasizing the role of autobiographical memory to one's sense of coherence across time. Experiences that become part of conscious or explicit memory seed how we come to represent ourselves in a neural map of "this is me" ${ }^{[2]}$. Explicit memories are the events recalled with conscious detail; including details of the event (semantic) and traces of oneself in the event (autobiographical) ${ }^{[2]}$. Memory impacts on the sense of self since autobiographical memory facilitates a sense of who one is across time; a sense that unfolds in the stories of our lives ${ }^{[36]}$. For instance, when discussing oneself a person might highlight a story that depicts his/her friendships in high school or family holiday rituals. Such stories narrate one's sense of self across time.

This ability to narrate our life to ourselves is a critical element of self-coherence since via this integration of our life stories we become aware of how past events impact on current experiences ${ }^{[27]}$. In the view of interpersonal neurobiology by directing attention to an individual's stories of self and their experiences the nurse can begin to grasp how an individual narrates his/her life to themselves. The process builds relationships ground in the nurse's in-depth knowing and understanding of the individual; a critical step that deepens engagement and a relationship that is based on knowing the patient and his/her unique experiences ${ }^{[7]}$. 
Building a sense of self-coherence is also a part of the healing process. In the case of recovery from serious mental illness (SMI), the loss of self-coherence is often a byproduct of how SMI impacts on the autobiography of self. This loss may occur if the experience of illness disturbs a previous identity, invites experiences of being different from others, or leads to a sense that one's thoughts about themselves are incomprehensible ${ }^{[24]}$. In Adnøy Eriksen and her colleagues' view (2014) having a sense of connection to a clinician allows an individual to be open and affected by others and initiates a process where an individual can begin to own his/her experiences. Individuals in recovery have told researchers what they needed were relationships that helped them make sense of themselves. In this light apprehending how stories weave into a narrative is a critical step in recovery since the experience helps individuals establish some meaning and control over their experiences ${ }^{[37]}$.

\section{Beyond engagement: What happens from here}

Ultimately PMH nurses need to articulate the psychotherapeutic processes operating within the engagement and relationship building processes so they might focus on the critical question: how does the nurse-patient relationship support individuals dealing with SMI to move towards the lives they choose? ${ }^{[12,38]}$. From an interpersonal neurobiology perspective, shared emotional states have in and of themselves a growth producing capacity because via this empathic connection the nurse helps individuals direct attention to their mental life as well their automatic way of responding to life situations. This ushers in awareness of alternative responses which when practiced facilitates new patterns of activation in the brain ${ }^{[27]}$. In this light the relationship work of PMH nurses has the potential to build new neural connections that increase mid-prefrontal lobe integration; integration that supports essential functions such as emotional balance and response flexibility ${ }^{[27]}$. In a similar model Wheeler (2011) outlined a growth process related to adaptive information processing ${ }^{[20]}$. Here dysregulation is seen as a byproduct of an individual splitting off particular experiences from the experience of self. The therapeutic relationship is aimed at integrating the thinking, feeling and remembering components of the self and self-experiences.

Joining with patients in a mindful, open, compassionate and non-judgmental manner also provides a relationship pathway that an individual may utilize to move towards wellness ${ }^{[7]}$. Individuals in recovery have told researchers about their relationships with PMH nurses; both ones where they had a sense of openness and trust and ones where they experienced clinicians as detached ${ }^{[24,33]}$. These individuals said they needed an authentic relationships as well as validation and support for their experiences. But they also needed "to get to the solution....Education, appropriate referrals, and

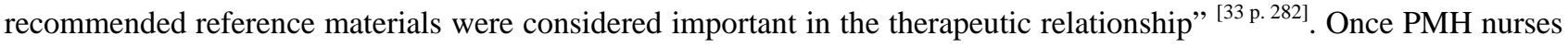
are clear about the cognitive strategies they are using to engage patients the relationship becomes a partnership where the nurse draws upon various strategies to help patients move towards the behaviors they see as useful and fit with their ideas on achieving wellness ${ }^{[38,39]}$.

\section{Conclusion}

The traditional PMH engagement framework of understanding meaning, deciphering needs, and grasping the patient's story within the relationship takes on a new dimension when merged with the language of interpersonal neuroscience. The language is particularly useful when structuring explanations of how the nurse harnesses attention and affect to forge connections; explanations which clarify the engagement process. Identifying the psychotherapeutic processes involved in engagement is vital to replicating them with some reliability and for training new PMH nurses in how to establish therapeutic relationships. To nurture continued growth of the specialty it is also essential to move beyond engagement to demonstrating how PMH nurses help individuals lead the life they define as meaningful ${ }^{[18]}$. Such work will require PMH nurses claim the time to be present with patients and to cultivate the openness and attunement that is the essential platform for the unfolding narrative. It will also require PMH nurses respect the purpose of their interpersonal practice and be clear about what they do to help individuals move towards wellness and a more meaningful life. 


\section{References}

[1] Oxford Dictionary (ND) Definition of mind. Available from:

http://www.oxforddictionaries.com/us/definition/american_english/mind.

[2] Siegel DJ. The developing mind. New York: Guilford Press; c1999. 394p.

[3] Peplau H. Peplau’s theory of interpersonal relations. Nurs Sci Q. 1997; 10(4): 162-167. http://dx.doi.org/10.1177/089431849701000407

[4] Cahill J, Paley G, Hardy G. What do patients find helpful in psychotherapy? Implications for the therapeutic relationship in mental health nursing. J Psychiatr Ment Health Nurs. 2012; 20(9):782-91. PMid:23151255

[5] Webster, S., Gallagher, S., Brown, P., Evans, J., Flynn, M., \& Lopez, V. The perceptions of nurses in their management of patients experiencing anxiety. J Nurse Educ Pract. 2012; (3): 38. http://dx.doi.org/ 10.5430/jnep.v2n3p38

[6] Crowe M, Luty, S. Patterns of response and non-response in interpersonal psychotherapy: A qualitative study. Psychiatry: Interpersonal and Biological Processes. 2005; 68(4): 337-349. PMid:16599400 http://dx.doi.org/10.1521/psyc.2005.68.4.337

[7] F Dziopa, K Ahern. What makes a quality therapeutic relationship in psychiatric/mental health nursing: A review of the research literature. Internet J Advanced Nurs Practice. 2008; 10(1): 7-7.

[8] Lego S. The one-to-one nurse-patient relationship. Perspect Psychiatr Care. 1999; 35: 4-23. http://dx.doi.org/10.1111/j.1744-6163.1999.tb00591.x

[9] Forchuk C., Reynolds W. Clients' reflections on relationships with nurses: comparisons from Canada and Scotland. J Psychiatr Ment Health Nurs. 2001; 8 (1): 45-51. http://dx.doi.org/10.1046/j.1365-2850.2001.00344.x

[10] McAndrew S, Chambers M, Nolan F, Thomas B, Watts P. Measuring the evidence: Reviewing the literature of the measurement of therapeutic engagement in acute mental health inpatient wards. Int J Ment Health Nurs 2013;

http://dx.doi.org/10.1111/inm.12044

[11] Shattell MM, Andes M, Thomas SP. How patients and nurses experience the acute care psychiatric environment. Nurs Inq. 2008; 15(3): 242-250. http://dx.doi.org/10.1111/j.1440-1800.2008.00397.x

[12] Browne G, Cashin A, Graham I. The therapeutic relationship and mental health nursing: it is time to articulate what we do! J Psychiatr Ment Health Nurs. 2012; 19(9): 839-843. http://dx.doi.org/10.1111/j.1365-2850.2012.01944.x

[13] Bridges J, Nicholson C, Maben J, Pope C, Flatley M, Wilkinson, C, ... \& Tziggili M. Capacity for care: meta - ethnography of acute care nurses' experiences of the nurse - patient relationship. J Adv Nurs. 2012; 69(4): 760-772. http://dx.doi.org/10.1111/jan.12050

[14] Cleary M, Hunt GE, Horsfall, J, Deacon M. Nurse-patient interaction in acute inpatient mental health units: A review and synthesis of qualitative studies. Issues Ment Health Nurs. 2012; 33: 66-79. http://dx.doi.org/10.3109/01612840.2011.622428

[15] Delaney KR, Johnson ME Metasynthesis of research on the role of psychiatric inpatient nurses: What is important to staff? J Am Psychiatr Nurs Assoc. 2014; 20(2): 125-137. PMid:24667372 http://dx.doi.org/10.1177/1078390314527551

[16] Berg A, Hallberg IR. Psychiatric nurses' lived experiences of working with inpatient care on a general team psychiatric ward. J Psychiatr Ment Health Nurs. 2000; 7(4): 323-333. http://dx.doi.org/10.1046/j.1365-2850.2000.00307.x

[17] Peplau H. Interpersonal constructs for nursing practice. In: O’Toole AW, Welt SR, editors. Interpersonal theory in nursing practice: Selected works of Hildegard E. Peplau. New York: Springer; 1989; 56-70.

[18] Cameron D, Kapur R, Campbell P. Releasing the therapeutic potential of the psychiatric nurse: a human relations perspective of the nurse-patient relationship. J Psychiatr Ment Health Nurs. 2005; 12(1): 64-74. http://dx.doi.org/10.1111/j.1365-2850.2004.00796.x

[19] Gallop R, O'Brien L. Re-establishing psychodynamic theory as foundational knowledge for psychiatric/mental health nursing. Issues in Ment Health Nurs. 2003; 24(2): 213-227. http://dx.doi.org/10.1080/01612840305302

[20] Wheeler K. A relationship-based model for psychiatric nursing practice. Perspect Psychiatr Care. 2011; 47: $151-159$. PMid:21707631 http://dx.doi.org/10.1111/j.1744-6163.2010.00285.x

[21] Deacon M, Warne T, McAndrew S. Closeness, chaos, and crisis: the attractions of working in acute mental health care J Psychiatr Ment Health Nurs. 2006; 13: 750-757. PMid:17087679 http://dx.doi.org/10.1111/j.1365-2850.2006.01030.x

[22] Siegel DJ. Toward an interpersonal neurobiology of the developing mind: Attachment, relationships, "mindsight "and neural integration. Infant Ment Health J. 2001; 22: 67-94. http://dx.doi.org/10.1002/1097-0355(200101/04)22:1<67::AID-IMHJ3>3.0.CO;2-G

[23] Peplau H. (1989). Interpersonal relationships: The purpose and characteristics of professional nursing. In O’Toole AW, Welt SR, editors. Interpersonal theory in nursing practice: Selected works of Hildegard E. Peplau New York: Springer; 1989; $42-55$. (Reprinted from Paper presented at Council of Hospital Services, Washington, D.C., February, 1965) 
[24] Adnøy Eriksen K, Arman M, Davidson L, Sundfør, B, Karlsson B. Challenges in relating to mental health professionals: Perspectives of persons with severe mental illness. Int J Ment Health Nurs. 2014; 23(2): 110-7. PMid:23718821 http://dx.doi.org/10.1111/inm.12024

[25] Browning S. Waite R. The gift of listening: JUST listening strategies. Nurs Forum. 2010; 45: 150-158. http://dx.doi.org/10.1111/j.1744-6198.2010.00179.x

[26] Decety J, Jackson PL. The functional architecture of human empathy. Behav Cogn Neurosci Rev. 2004; 3(2): 71-100. http://dx.doi.org/10.1177/1534582304267187

[27] Siegel DJ. An interpersonal neurobiology approach to psychotherapy. Psychiatr Ann. 2006; 36: 248-256.

[28] Fonagy P. The mentalization-focused approach to social development. In Busch FN, editor. Mentalization: Theoretical considerations, research findings, and clinical implications. New York: Taylor \& Francis; 2008. 3-56.

[29] Bateman A, Fonagy P. Psychotherapy for borderline personality disorder. New York: Oxford University Press. c 2004. 381p.

[30] Slade A. Working with parents in child psychotherapy engaging the reflective function. In Busch FN, editor. Mentalization: Theoretical considerations, research findings, and clinical implications .New York: Taylor \& Francis; 2008; 207-234.

[31] Freshwater D, Taylor BJ, Sherwood G., editors. International textbook of reflective practice in nursing. United Kingdom: John Wiley. c2008. 244p.

[32] O’ Brien L. Nurse-client relationships: The experience of community psychiatric nurses. Aust N Z J Ment Health Nurs. 2000; 9(4): 184-194. http://dx.doi.org/10.1111/j.1365-2869.2004.00395.x

[33] Shattell MM, Starr SS, Thomas SP. Take my hand, help me out:” Mental health service recipients' experience of the therapeutic relationship. Int J Ment Health Nurs. 2007; 16: 274-284. http://dx.doi.org/10.1111/j.1447-0349.2007.00477.x

[34] Stern DN. The present moment in psychotherapy and everyday Life (Norton Series on Interpersonal Neurobiology). New York: WW Norton \& Company. c2004. 283p.

[35] Hall J M, Powell J. Understanding the person through narrative. Nurs Res Pract 2011. Article ID 293837, 10 pages. http://dx.doi.org/10.1155/2011/293837

[36] Siegel DJ. The mindful brain. Reflection and attunement in the cultivation of well being. New York: W.W. Norton. c2007. 387p.

[37] Crowe M, Carlyle D, Farmer R. Clinical formulation for mental health nursing practice. J Psychiatr Ment Health Nurs. 2008; 15: 800-807. http://dx.doi.org/10.1111/j.1365-2850.2008.01307.x

[38] Happell B. Mental health nursing: what it is or what it does? Int J Ment Health Nurs. 2011; 20: 1. PMid:21199238 http://dx.doi.org/10.1111/j.1447-0349.2010.00727.x

[39] Crowe M, Whitehead L, Carlyle D., McIntosh V, Jordan J, Joyce P, Carter J. The process of change in psychotherapy for depression: helping clients to reformulate the problem. J Psychiatr Ment Health Nurs. 2012; 19(8): 681-689. PMid:22070862 http://dx.doi.org/10.1111/j.1365-2850.2011.01840.x 